Article

\title{
Conceptualizing and Measuring the Quality of Democracy: The Citizens' Perspective
}

\author{
Dieter Fuchs ${ }^{1, *}$ and Edeltraud Roller ${ }^{2}$ \\ ${ }^{1}$ Department of Social Science, University of Stuttgart, 70174 Stuttgart, Germany; \\ E-Mail: dieter.fuchs@sowi.uni-stuttgart.de \\ 2 Department of Political Science, Johannes Gutenberg University Mainz, 55099 Mainz, Germany; \\ E-Mail: roller@politik.uni-mainz.de \\ * Corresponding author
}

Submitted: 29 September 2017 | Accepted: 7 December 2017 | Published: 19 March 2018

\begin{abstract}
In recent years, several measurements of the quality of democracy have been developed (e.g. Democracy Barometer, Varieties of Democracy Project). These objective measurements focus on institutional and procedural characteristics of democracy. This article starts from the premise that in order to fully understand the quality of democracy such objective measurements have to be complemented by subjective measurements based on the perspective of citizens. The aim of the article is to conceptualize and measure the subjective quality of democracy. First, a conceptualization of the subjective quality of democracy is developed consisting of citizens' support for three normative models of democracy (electoral, liberal, and direct democracy). Second, based on the World Values Survey 2005-2007, an instrument measuring these different dimensions of the subjective quality of democracy is suggested. Third, distributions for different models of democracy are presented for some European and non-European liberal democracies. They reveal significant differences regarding the subjective quality of democracies. Fourth, the subjective quality of democracy of these countries is compared with the objective quality of democracy based on three indices (electoral democracy, liberal democracy and direct popular vote) developed by the Varieties of Democracy (V-Dem) Project. Finally, further research questions are discussed.
\end{abstract}

\section{Keywords}

democracy; measuring democracy; models of democracy; political culture; quality of democracy; social science concepts; subjective quality of democracy; varieties of democracy

\section{Issue}

This article is part of the issue "Why Choice Matters: Revisiting and Comparing Measures of Democracy", edited by Heiko Giebler (WZB Berlin Social Science Center, Germany), Saskia P. Ruth (German Institute of Global and Area Studies, Germany), and Dag Tanneberg (University of Potsdam, Germany).

(C) 2018 by the authors; licensee Cogitatio (Lisbon, Portugal). This article is licensed under a Creative Commons Attribution 4.0 International License (CC BY).

\section{Introduction}

In recent years, several measurements of the quality of democracy have been developed. Focussing on political regimes classified as democracies they examine differences in the quality of these democracies. These measurements include the Democracy Barometer (Bühlmann, Merkel, Müller, \& Weßels, 2012) and the Varieties of Democracy (V-Dem) Project (Coppedge, Lind- berg, Skaaning, \& Teorell, 2016). As these measurements focus on institutional and procedural characteristics of democracy, they can be called objective measurements.

This article deals with subjective measurements of the quality of democracy which are based on the perspective of citizens. It starts from the premise that in order to fully understand the quality of a democracy, objective measurements have to be complemented by subjective measurements at the level of the citizens. In 
some cases, the above-mentioned objective measurements use such subjective indicators as well, particularly if objective indicators for theoretical constructs are missing. For example, the Democracy Barometer uses citizens' confidence in the legal system as an indicator of the quality of the legal system (Merkel et al., 2016, p. 17). However, this pragmatic strategy is questionable because objective structures and subjective evaluations of citizens constitute entirely different dimensions and can vary independently. It is possible that objective measurements of the democratic structure and processes are of high quality whereas subjective measurements of these objects are of low quality and vice versa.

The aim of this article is to propose a conceptualization and measurement of the subjective quality of democracy. Two assumptions are central. First, the subjective quality of democracy consists of citizens' support for normative conceptions of democracy. Accordingly, the more citizens support normative conceptions of democracy, the higher the subjective quality of a democracy. We want to point out that the subjective quality of democracy does not consist of citizens' evaluations of the democracy in their own country which is a quite common conception (see section 2) but instead it consists of their basic conceptions of democracy. Our conceptualization is compatible with a situation where citizens prefer democracy in general while at the same time critically evaluate the democracy in their own country. Klingemann (2014), who introduced the term "critical citizens" for such individuals, could demonstrate empirically that this type of citizen is widespread in old and new democracies and that these citizens are inclined to demand democratic reforms. Hence, the existence of critical citizens does not indicate low subjective quality of a democracy but instead is a sign of a living democracy and of high subjective quality of democracy. Second, in conceptualizing citizens' support for normative conceptions of democracy we draw on the established notion of different models of democracy and relate the subjective quality of democracy to these models. In particular, we distinguish between three well-established normative models, i.e. electoral, liberal and direct democracy, which build a hierarchy from less to more demanding models. This hierarchy is taken into account when conceptualizing the subjective quality of democracy.

The analysis proceeds in four steps. First, the state of the art on subjective quality of democracy is presented by discussing recently published studies with comparable goals but differing with respect to the central aspects of our analysis. Second, after presenting arguments for why objective measurements of the quality of democracy have to be complemented by subjective measurements at the level of citizens, a conceptualization of the subjective quality of democracy is developed including definitions of different dimensions of subjective quality of democracy. Third, based on the sixth wave of the World Values Survey (WVS) 2005-2007 an instrument measuring different dimensions of the subjective qual- ity of democracy is suggested. Fourth, distributions for these different dimensions (normative conceptions of democracy) are presented for some European and nonEuropean liberal democracies and compared to objective measurements of the quality of democracy based on three indices (electoral democracy, liberal democracy and direct popular vote) developed by the V-Dem Project (Coppedge et al., 2017). In the concluding chapter, further research question are discussed.

\section{State of the Art}

Recently, three studies have been published which are of relevance for our study on the subjective quality of democracy. Two studies claim that objective measurements of the quality of democracy have to be complemented by subjective measurements (Mayne \& Geissel, 2016; Pickel, Breustedt, \& Smolka, 2016) while a third study develops refined measures of citizens' attitudes towards democracy and constructs different models of democracy on this basis (Ferrín \& Kriesi, 2016)

Mayne and Geissel (2016, p. 634) state the goal of their analysis concisely in the title of their article: "Putting the Demos back into the Concept of Democratic Quality". They argue that the concept of democratic quality encompasses two dimensions, namely an institutional opportunity-structure component and a citizen component. While several conceptualizations of the quality of democracy are available for the institutional dimension, conceptualizing the citizen component "which refers to the ways in which citizens can and do breathe life into existing institutions opportunities" is a neglected research topic (Mayne \& Geissel, 2016, pp. 635-637). To grasp the citizen component they develop an analytic framework and introduce two theoretical dimensions. On one hand, by explicitly referring to the V-Dem Project they identify three key models of democracy: minimal-elitism, liberal-pluralism as well as participatory and deliberative democracy (Mayne \& Geissel, 2016, pp. 636-639). On the other hand, they distinguish three key citizens' dispositions, namely democratic commitments, political capacities and political participation (Mayne \& Geissel, 2016, p. 634). For each combination of key models of democracy and key citizens' dispositions, they suggest specific attitudes or specific modes of behaviour capturing the democratic quality of the citizen component (Mayne \& Geissel, 2016, p. 641). For the minimal-elitism model, for example, they list acceptance of elected elites as sole decision makers and commitment to comply with law of the land as forms of democratic commitment.

While the proposed attitudes and modes of behaviour involve measurable constructs, the authors do not list concrete indicators from available surveys and data collections. Furthermore, a definition of the democratic quality of the citizen component is missing as well as information on how this variety of attitudes and modes of behaviour is related to the democratic quality of the citizen component. 
Pickel et al. (2016, p. 646) initially praise the new indices for measuring the quality of democracy such as the Democracy Barometer as being innovative achievements. However, they also criticize these indices for relying mainly on macro indicators and neglecting the micro level of citizens which might involve a biased perspective. Pickel et al. (2016, p. 645) do not start their analysis with the premise that the inclusion of the citizen perspective is a necessity when measuring the quality of democracy; instead they ask the precedent question "why include the citizens' perspective?" According to them, it first has to be demonstrated that the inclusion of the citizens' perspective improves the measurement of the quality of government. To answer this question, they compare a measurement of the democratic quality at the macro level with a measurement at the micro level of citizens. For the macro level, they rely on Democracy Barometer data and for the micro level they use data on views and evaluations of democracy collected by the European Social Survey 2012. The measurement instrument of the European Social Survey 2012 asks for several democratic principles (e.g. protection of rights of minority groups, equal treatment by the courts) how important they are for democracy in general (views) and to what extent these principles apply in their country (evaluations). Pickel et al. (2016, p. 648) relate the individual level indicators of the European Social Survey to the macro level concepts of the Democracy Barometer. Their empirical analysis of 20 European democracies reveal similarities as well as considerable differences between the macro level data on the one hand and the views and evaluations of democracy on the other. Pickel et al. (2016, p. 653) conclude that citizens views and evaluations "provide a meaningful complementary perspective to 'objective' measures of the quality of democracy".

By demonstrating empirically that objective and subjective evaluations of the quality of democracy differ, the study of Pickel et al. (2016) provides evidence for including the subjective perspective when measuring quality of democracy. Their study does not include a definition of the subjective quality of democracy, but this was not their leading question. In addition, they do not distinguish between normative models of democracy.

The already-mentioned data of the European Social Survey 2012 were analysed in a book edited by Ferrín and Kriesi (2016). Based on the above-described item battery, the authors construct three models of democracy (liberal, social justice and direct democracy) on the level of views and on the level of evaluations. Although they construct different normative models of democracy, the authors do not address the topic of the subjective quality of democracy. The main goal of their book is to develop new concepts and measurements of political support and political legitimacy (Ferrín \& Kriesi, 2016, pp. 12-13).

The following analysis distinguishes from these three contributions in several respects. First, a conceptualization of the subjective quality of democracy is developed covering definitions of the different dimensions of the subjective quality of democracy. Second, the subjective quality of democracy consists of citizens' support for normative models of democracy. It does not refer to citizens' evaluations of the democracy in their country. Third, a measurement of the subjective quality of democracy is proposed on the basis of the WVS 2005-2007 and empirical findings are presented for European as well as non-European democracies. Fourth, these results are compared to objective measurements of the quality of democracy developed by the V-Dem Project (Coppedge et al., 2017).

\section{Conceptualizing the Subjective Quality of Democracy}

Before conceptualizing the subjective quality of democracy, we present arguments for why it is reasonable to complement objective measurements of the quality of democracy with subjective ones and propose a general strategy for how to do this.

The starting point is the paradigm of political culture and its fundamental idea of there being a separation between an institutional structure and a political culture (Almond \& Verba, 1963). Political culture is based upon the (aggregated) political attitudes of the citizens and thus has a subjective basis while the institutional structure refers to an objective level. The innovative notion of Almond and Verba is the introduction of the citizen perspective into political science and providing arguments for its significance. Its relevance is expressed in the following postulate of the political culture paradigm: a political regime is more stable, the stronger the congruency between the institutional structure and the political culture (Almond \& Verba, 1963, p. 21). In subsequent research on democratic regimes, the concept of political culture has been defined more precisely. Nowadays it is a widely accepted notion among political scientists that the stability, as well as the functioning of a democracy, depends mainly on citizens' support of democracy (e.g. Diamond, 1999; Easton, 1975; Linz \& Stepan, 1996; Lipset, 1981).

We start from the assumption that this basic postulate of the political culture paradigm can be expanded to the quality of democracy, i.e. support of democracy is not only of relevance for the stability and the functioning of democracy but also for the quality of democracy. Based on this premise we develop our general strategy of conceptualizing the subjective quality of democracy. In doing so we refer to the concept of support of democracy. It is very common to distinguish between at least three levels of support of democracy: commitment to democratic values and principles, support of the democratic regime of one's own country, and support of political authorities (e.g. Dalton, 2004; Fuchs, 2007; Norris, 2011). These three levels create a hierarchy; the highest level consists of the commitment to democratic values-including the value of democracy-and democratic principles. It is the most important level because 
it determines the support of democracy at the lower levels, specific democratic attitudes, as well as democratic modes of behaviour. We assume that the commitment to democratic values and principles is of relevance for the subjective quality of democracy in at least in three ways. First, the unambiguous and doubtless support of democracy implies that citizens do not see any alternative to this form of government. This can be conceived as a criterion for the subjective quality of democracy. Second, citizens' basic democratic values and principles are used for evaluating the democracy of one's own country. This confrontation may result in citizens demanding reforms to improve their democracy which is regarded as a feature of a vibrant democracy and thus as a criterion for the subjective quality of democracy. Third, the general commitment to democratic values and principles influences more specific democratic attitudes and modes of behaviour. For example, it could motivate citizens to participate actively and cooperatively to both articulate their interests, as well as to engage in the political decision-making processes (Putnam, 1993). These are characteristics of a living democracy and of a high quality of democracy.

To summarize: when interested in the quality of a democracy, the perspective of citizens has to be taken into account because citizens are the ultimate sovereign of democracy. Their attitudes and behaviour depend decisively on their commitment to democratic values and principles. This is the starting point for conceptualizing and measuring the subjective quality of a democracy. The subjective quality of democracy does not refer to citizens' evaluations of the democracy of their country. The proposed subjective measurement is not intended to replace objective measurements of the quality of democracy but to complement them.

In conceptualizing the subjective quality of democracy we use the "framework for the analysis of data" developed by Munck and Verkuilen (2002, updated in Munck, 2009, p. 15) and add some ideas from the analysis of social science concepts by Goertz (2006). According to Munck (2009, p. 15), the challenge of conceptualization consists of two tasks: the "identification of at- tributes" used to define the concept, and the "vertical organization of attributes by level of abstraction". This vertical organization includes three levels: the highest level is the concept, the next level comprises the attributes of the concept, and the lowest level includes the components of attributes. These components of attributes are also called "leaves" and serve as a point of reference for the measurement (Munck, 2009, p. 21). As a result a so-called conceptual tree can be developed (Figure 1); it is comparable to the "three-level concepts" by Goertz (2006, pp. 50ff.). Munck (2009) illustrates his three-level model of democracy with objective criteria by referring mainly to Dahl (1989).

For our purpose, this model has to be specified for the subjective quality of democracy. Hence, the concept level consists of the subjective quality (SQ) of democracy (Figure 3 ). To identify the attributes we draw on a conclusive notion of the V-Dem Project. Coppedge et al. (2016) argue that the question regarding the quality of democracy depends largely on the normative standards used for evaluation. Accordingly, they distinguish several models of democracy and suggest a number of components and indicators for each model with which the quality of democracy can be assessed. The idea of the V-Dem Project is to "offer a fairly comprehensive accounting of the concept of democracy as it is employed today" (Coppedge et al., 2011, p. 253). Consequently, they use a broad list of models including electoral, liberal, participatory, deliberative, and egalitarian democracy (Coppedge et al., 2016). In the following, we pursue a more simplified conceptual approach and reduce the list to three established models of democracy: electoral, liberal and direct democracy. These models are common both in macro-level research on objective measurements of the quality of democracy and in micro-level research on the support of democracy. For example, such models have been suggested by Altman (2013), Diamond (1999) as well as Ferrín and Kriesi (2016). Using these three models implies that hybrid models of democracy such as delegative democracy (Morlino, 2009; O’Donnell, 1994) are excluded from the analysis. The advantage of focusing on these three established models, among other things,

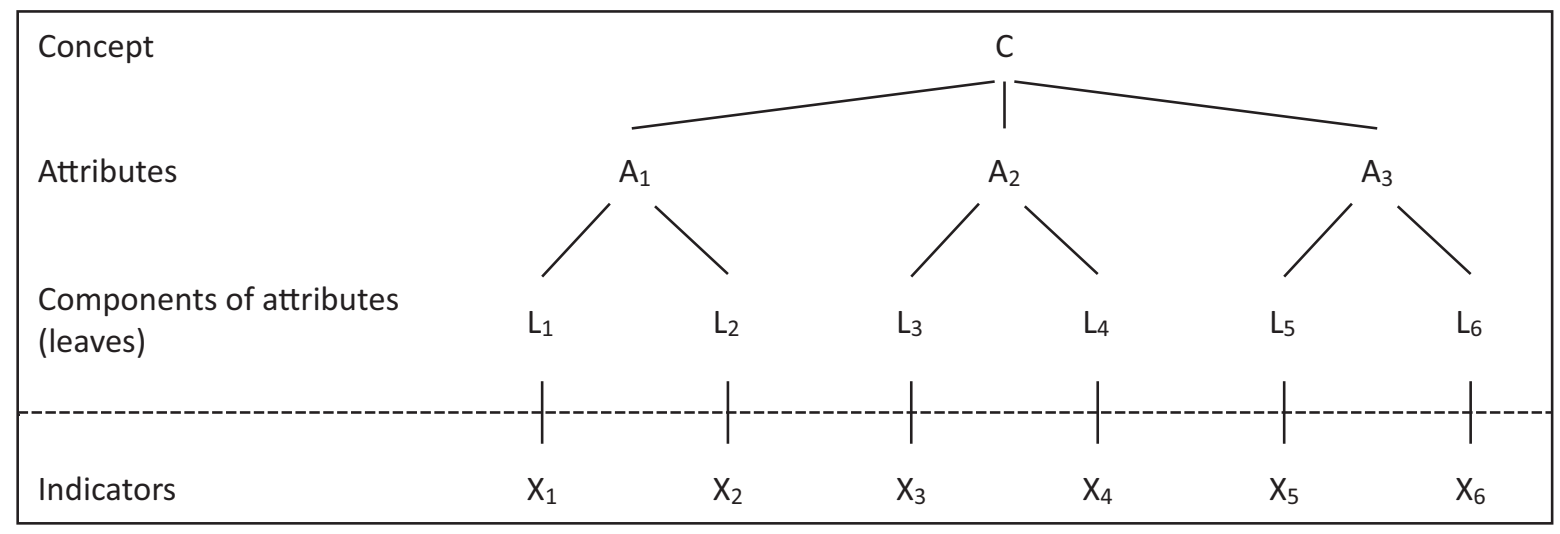

Figure 1. The logical structure of concepts (based on Munck, 2009). 
Figure 2. Models of democracy (institutions, hierarchical order).

\begin{tabular}{lccc}
\hline & Electoral democracy & Liberal democracy & Direct democracy \\
\hline Competitive elections & 1 & 1 & 1 \\
Liberal rights & 0 & 1 & 1 \\
Direct participation & 0 & 0 & 1 \\
\hline
\end{tabular}

Notes: 1 = assignment; 0 = non-assignment.

is parsimony and the possibility of establishing a systematic relationship between subjective and objective measurements of the quality of democracy.

In defining these three models we rely on concise formulations of the V-Dem Project (Coppedge et al., 2016, pp. 582-583): electoral democracy "embodies the core value of making rulers responsive to citizens through competition for the approval of a broad electorate during periodic elections". Liberal democracy "embodies the intrinsic value of protecting individual and minority rights against a potential 'tyranny of the majority' and state repression more generally". Participatory democracy "embodies the values of direct rule and active participation by citizens in all political processes". These three models can be ordered along a normative hierarchy, i.e. the more demanding models include the less demanding ones (Coppedge et al., 2016; Diamond, 1999). Electoral democracy is above all defined by the institution of competitive elections; liberal democracy additionally includes liberal rights, and direct democracy covers forms of direct participation as well (Figure 2).

Attitudes towards these three models of democracy constitute the attributes of the subjective quality of democracy on the second level (Figure 3). In addition to these attitudes towards the three normative models of democracy, a basic and generalized attitude towards democracy is postulated. Only if democracy in general is clearly supported in the first instance does the question of support for different normative models of democracy arise. As a result, the subjective quality of democracy is defined by four attitudes that create the following nor- mative hierarchy: democracy (D), electoral democracy (ED), liberal democracy (LD) and direct democracy (DD).

We started from the assumption that the first and minimal criterion of the subjective quality of democracy is support of democracy as a form of government in general. Consequently, the subjective quality (SQ) of democracy (D) could be defined as follows: independent of the specific model of democracy institutionalized in a country, the minimal subjective quality of the country's democracy becomes higher, the more citizens unambiguously and doubtlessly support democracy as a form of government.

To judge a country's subjective quality of democracy a theoretical criterion is needed that determines the minimum percentage of citizens who support democracy. As a rule of thumb the majority rule can be used; i.e. at least $50 \%$ of the citizens have to support democracy.

On a structural level, electoral democracy is defined by the institutionalization of free, competitive, fair and frequent elections; this institution unanimously makes up the indispensable core of democracy (Dahl, 1989; Diamond, 1999). On the subjective level, a corresponding citizens' attitude towards electoral democracy is support of important characteristics of the institution of elections. However, this criterion has to be supplemented by another because, as we know from autocracy research, there are many autocracies which hold seemingly democratic elections (Levitsky \& Way, 2010; Schedler, 2006). Hence, even at this objective level, the institution of elections does not suffice to separate democracy from autocracy. A similar situation exists on the subjective level

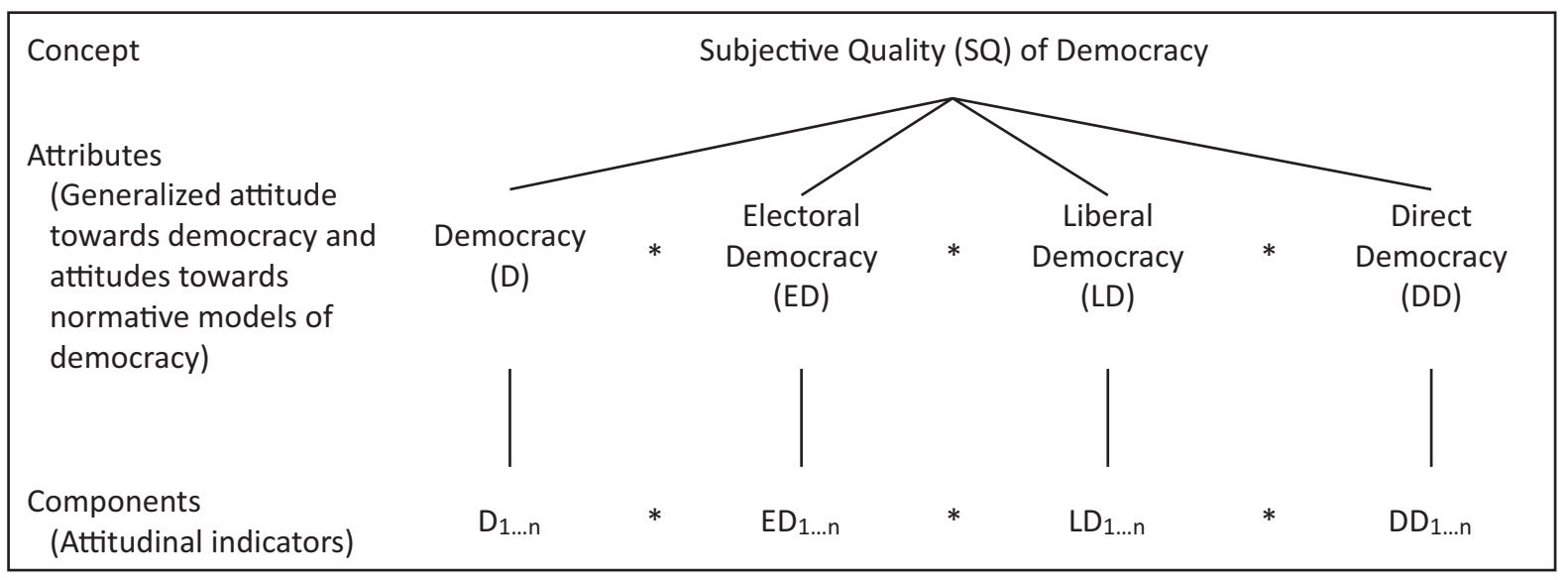

Notes: ${ }^{*}=$ Multiplication.

Figure 3. Conceptual structure of the subjective quality of democracy. 
when citizens support important characteristics of elections without showing a clear preference for democracy. Consequently, support for elections has to be linked to support of democracy.

Such a link between two attributes is defined by Goertz (2006, pp. 50ff.) as an "AND"-relationship and by Munck (2009, p. 50) as an "interactive, noncompensatory"-relationship. As a logical expression of this "AND"relationship Goertz (2006, p. 61) uses the multiplication sign "*". If the absence of an attribute in an "AND"relationship is coded as 0 , then a multiplication of both attributes equals also 0 , thus the concept does not exist. Following Goertz, a multiplication sign between democracy (D) and electoral democracy (ED) is included in Figure 3.

On the basis of the previous argument, a second definition of the subjective quality of democracy (SQ) can be given which refers to electoral democracy (ED): if an electoral democracy is fully institutionalized in a country, the quality of this electoral democracy becomes higher, as more citizens support democracy as a form of government and support the most important characteristics of electoral democracy.

The first part of this definition points to a further important characteristic of our conceptualization of the subjective quality of democracy. It says that assessing the subjective quality of electoral democracy presupposes the institutionalisation of an electoral democracy in a country. The same logic applies to the following models of liberal democracy and direct democracy. This kind of reference to the institutional dimension of democracy is constitutive for the conceptualization of the subjective quality of democracy. In that way, the paradoxical coexistence of there being a high subjective quality of democracy within a non-democratic regime is excluded on the conceptual level.

Liberal democracy is a more demanding concept; it presupposes electoral democracy and complements it by the institutionalization of values which originate from the tradition of liberal thought. According to many authors (e.g. Dahl, 1989; Diamond, 1999; Merkel, 2004), a liberal democracy is the only type of democracy which sufficiently corresponds to the meaning of democracy. In order to be meaningful, elections need to be complemented by the guarantee of political rights and civil liberties. The third dimension of the subjective quality of democracy (SQ) referring to liberal democracy (LD) can be defined as follows: if a liberal democracy is fully institutionalized in a country, then the quality of this liberal democracy is higher, the more citizens are in favour of electoral democracy while simultaneously supporting the most important characteristics of liberal democracy. The "AND"-relationship between the subjective quality of electoral democracy and liberal democracy is marked by a multiplication sign in Figure 3.

Direct democracy is characterized by direct participation of citizens in political decisions. Historically, a pure form of direct democracy only existed within the city-state of the ancient Athens, where all important issues were decided by the people themselves, and the people literally governed themselves. In contemporary nation-states, organized as representative democracy, the model of direct democracy consists of the supplementation of representative democracy by forms of direct citizen participation such as referendums (Altman, 2011).

In defining the subjective quality of direct democracy a conceptual problem arises. To what extent do forms of direct participation have to be institutionalized so that we are able to refer to them as a new type of democracy which can be called direct democracy? Creating a threshold is difficult. However, the notion of supplementing representative democracy with forms of direct citizen participation involves the idea of a continuum with a purely representative democracy at one end and a representative democracy which incorporates some degree of direct participation at the other end. Usually, Switzerland with by far the most forms of direct participation is placed at the end of this continuum.

The ambiguity of the concept of direct democracy has also consequences for the definition of the subjective quality of this model. In contrast to electoral democracy and liberal democracy, it cannot start from the premise that direct democracy is fully institutionalized. This is why the definition of the subjective quality (SQ) of direct democracy (DD) has to take into account different degrees of direct participation: provided that a liberal democracy has institutionalized some forms of direct participation and therefore can be understood as a direct democracy, then the subjective quality of the direct democracy is higher, the stronger citizen support for these forms of direct participation is. Again, the "AND"relationship between the subjective quality of liberal democracy and direct democracy is marked by a multiplication sign in Figure 3.

The construction of an "AND"-relationship between the subjective quality of the three models of democracy is the technical implementation of the assumption that the three models form a normative hierarchy, i.e. the more demanding models include the less demanding ones (cf. Figure 2). At the objective level, the V-Dem Project constructs the indices for the different models in a similar way (Coppedge et al., 2016, 2017).

The next and lowest level of the conceptual tree is made up of components of attributes. In the conceptual structure in Figure 3, these refer to the attitudinal indicators of the attributes and are addressed in the next section.

\section{Measuring the Subjective Quality of Democracy}

For the measurement of the subjective quality of democracy, survey data are required asking for support of democracy in general and support of the electoral, liberal, and direct model of democracy. Currently, only two comparative representative surveys including such indi- 
cators are available: the European Social Survey 2012 covering only European countries and the WVS including European as well as non-European countries. In order to be able to include non-European countries as well, we draw on the sixth wave of the WVS (2005-2007). The indicators and the construction of the corresponding indices "Democracy (D)", "Electoral Democracy (ED)", "Liberal Democracy (LD)", and "Direct Democracy (DD)" are described in Table 1.

The different models of democracy represent normative models, therefore each indicator assigned to each construct constitutes a necessary feature of the respective model. In order to construct the four indices, each indicator measuring support of democracy or democratic principles is dichotomized. Respondents who support democracy in general or electoral democracy or liberal democracy or direct democracy are coded 1; those who do not support democracy or electoral democracy or liberal democracy or direct democracy are coded 0 . Through the multiplication of two measurements one gets a 0 if any one of the measurements is 0 ; in this case, the respective democratic attitude does not exist.
For constructing the index "Democracy (D)" an indicator is available which directly asks whether a democratic political system is good or bad. Yet, as respondents may associate different things with democracy, a correct understanding of democracy which at least roughly corresponds with the theoretical definition cannot be assumed. However, the understanding can be checked using two indicators which unequivocally measure a rejection of autocracy. One indicator asks whether one considers a "strong leader who does not have to bother with parliament and elections" to be good or bad; the other asks the same for "having the army rule". Initially the three indicators, measured on a four-point scale, are dichotomized separating between good and bad. Respondents who support democracy in general are coded 1, those who do not support democracy are coded 0 . In order to correct for a reasonable understanding of democracy, the multiplication rule is applied. If a respondent assesses at least one of the two autocracy items as good, 0 is assigned; the multiplication with support of democracy results in 0 , which means that the respondent does not support democracy unambiguously and doubtlessly.

Table 1. Measuring the subjective quality of democracy on the basis of the WVS 2005-2007.

\begin{tabular}{|c|c|c|}
\hline Quality dimension & Original Items & Measurement \\
\hline Democracy (D) & $\begin{array}{l}\text { - Having a democratic political system } \\
\text { - Having a strong leader who does } \\
\text { not have to bother with parliament } \\
\text { and elections? } \\
\text { - Having the army rule } \\
\text { ( } 1=\text { very good, } 2=\text { fairly good, } \\
3=\text { fairly bad, } 4=\text { very bad) }\end{array}$ & $\begin{array}{l}\text { - All three variables are dichotomized }(1-2=1 ; 3-4=0) \text {. } \\
\text { - Construction of index "rejection of autocracy": } 1=\text { if } \\
\text { "strong leader" equal } 0 \text { or "army rule" equal } 0 ; 0=\text { all } \\
\text { other logical combinations } \\
\text { - Construction of index "Democracy (D)" = democratic } \\
\text { system * index "rejection of autocracy" } \\
(1=\text { "democratic system" equal } 1 * \text { "rejection of } \\
\text { autocracy" equal } 1 ; 0=\text { all other multiplicative terms) }\end{array}$ \\
\hline $\begin{array}{l}\text { Electoral } \\
\text { Democracy (ED) }\end{array}$ & $\begin{array}{l}\text { - People choose their leaders in free } \\
\text { elections } \\
\text { - Women have the same rights as } \\
\text { men ( } 1=\text { not an essential } \\
\text { characteristic democracy...10 = an } \\
\text { essential of characteristic of } \\
\text { democracy) }\end{array}$ & $\begin{array}{l}\text { - Both variables are dichotomized }(1-7=0 ; 8-10=1) \text {. } \\
\text { - Construction of index "elections": } 1=\text { if "free elections" } \\
\text { equal } 1 \text { and "same rights" equal } 1 ; 0=\text { all other logical } \\
\text { combinations } \\
\text { - Construction of index "Electoral Democracy (ED)" } \\
=\text { index "elections" * index "Democracy (D)" } \\
(1=\text { "elections" equal } 1 \text { * index "Democracy (D)" } \\
\text { equal } 1 ; 0=\text { all other multiplicative terms) }\end{array}$ \\
\hline $\begin{array}{l}\text { Liberal } \\
\text { Democracy (LD) }\end{array}$ & $\begin{array}{l}\text { - Civil rights protect people's liberty } \\
\text { against oppression. } \\
\text { (1= not an essential characteristic } \\
\text { of democracy...10 = an essential } \\
\text { characteristic of democracy) }\end{array}$ & $\begin{array}{l}\text { - Variable "civil rights" is dichotomized }(1-7=0 \text {; } \\
8-10=1) \text {. } \\
\text { - Construction of index "Liberal Democracy (LD)" = } \\
\text { variable "civil rights" * index "Electoral Democracy (ED)" } \\
(1=\text { "civil rights" equal } 1 \text { * index "Electoral Democracy } \\
\text { (ED)" equal } 1 ; 0=\text { all other multiplicative terms) }\end{array}$ \\
\hline $\begin{array}{l}\text { Direct } \\
\text { Democracy (DD) }\end{array}$ & $\begin{array}{l}\text { - People can change the laws in } \\
\text { referendums. ( } 1=\text { not an essential } \\
\text { characteristic of democracy...10 = } \\
\text { an essential characteristic } \\
\text { of democracy) }\end{array}$ & $\begin{array}{l}\text { - Variable "referendums" is dichotomized }(1-7=0 \text {; } \\
8-10=1) \text {. } \\
\text { - Construction of index "Direct Democracy (DD)" } \\
=\text { variable "referendums" * index "Liberal Democracy } \\
\text { (LD)" ( } 1=\text { "referendums" equal } 1 \text { * index "Liberal } \\
\text { Democracy (LD)" equal } 1 ; 0=\text { all other multiplicative } \\
\text { terms) }\end{array}$ \\
\hline
\end{tabular}

Notes: ${ }^{*}=$ Multiplication . 
For measuring the support of electoral, liberal, and direct democracy an item battery covering several principles of democracy (e.g. people choose their leaders in free elections) is used. The respondents are asked for each whether it is an essential characteristic of democracy or not. The scale ranges from 1 (= not an essential characteristic of democracy) to 10 (= an essential characteristic of democracy). In order to measure clear support of a democratic principle and to avoid a soft middle category, the scale is dichotomized as follows: The values 8-10 are coded 1 and the remaining values are coded 0 . Of course, other modes of dichotomizing would produce different results.

Support of electoral democracy is measured by two indicators: "people choose their leaders in free elections" and "women have the same rights as men". They refer to two basic principles of electoral democracy, namely free elections and political equality. The second indicator "women have the same rights as men" is ambiguous because the protection of women's rights can also be regarded as a criterion for a liberal democracy. But since, according to Dahl (1989), elections are not sufficiently defined without the criterion of equality, this indicator is used as a proxy for the equality criterion. Only if both of these principles, i.e. free elections and political equality, are considered to be essential characteristics of democracy, can reasonable support of electoral democracy be assumed. In order to construct the index "Electoral democracy (ED)" the multiplication rule with "Democracy (D)" is applied.

The indicator measuring liberal democracy represents an appropriate operationalization of a basic principle of negative liberties: "civil rights protect people's liberty against oppression". Finally, the indicator for direct democracy focuses on a central form of direct participation of the citizens: "People can change the laws in referendums". Referendums are the dominant form in which direct democracy can be realized in modern democracies. For constructing the respective indices, "Liberal Democ- racy (LD)" and "Direct Democracy (DD)", the values are multiplied by the preceding models.

As the item battery of the WVS asks whether each element is an essential characteristic of democracy it might be criticized for measuring primarily a cognitive and not the conceptually demanded evaluative dimension. In the first instance, we would argue that the criterion "essential" includes more of an evaluative component than the criterion "important" used by the comparable battery of the European Social Survey 2012. At any rate, it is plausible to assume that the specific characteristics of democracy gathered by the WVS clearly has an evaluative meaning, if democracy is unambiguously preferred as a form of government (see multiplication with “Democracy (D)" in Table 1).

\section{Empirical Results}

To demonstrate the applicability of the proposed measure of the subjective quality of democracy and to compare it with an objective measure a sample of five European and five non-European liberal democracies was selected (France, Germany, Norway, Sweden, Switzerland vs. Brazil, India, South Korea, Taiwan, USA). Liberal democracies were identified on the basis of the liberal democracy index of V-Dem (Coppedge et al., 2017). The scale of this index ranging from 0 to 1 ; we define that values greater than 0.5 indicate the existence of a liberal democracy. This definition is validated by the democracy index of Freedom House (2017); all selected countries are classified as liberal democracies by this index, too.

Table 2 includes the distribution of the four indices measuring the subjective quality of democracy (columns "subjective") as well as data for the objective quality of democracy for each of the three normative models (columns "objective"). The objective data was provided by V-Dem (Coppedge et al., 2017). The values for the three indices-electoral democracy index, liberal democracy index, direct popular vote index-vary from 0 to 1 .

Table 2. Subjective and objective quality of democracy in selected liberal democracies.

\begin{tabular}{lccccccc}
\hline & \multicolumn{2}{c}{ Democracy (D) } & \multicolumn{2}{c}{ Electoral Democracy (ED) } & \multicolumn{2}{c}{ Liberal Democracy (LD) } & \multicolumn{2}{c}{ Direct Democracy (DD) } \\
\cline { 2 - 7 } Country & Subjective & Subjective & Objective $^{1}$ & Subjective $^{\text {Objective }}{ }^{2}$ & Subjective $^{\text {Objective }^{3}}$ \\
\hline Norway & 81.7 & 74.2 & 0.92 & 57.5 & 0.89 & 44.0 & 0.3 \\
Switzerland & 79.8 & 70.8 & 0.91 & 64.8 & 0.87 & 62.2 & 0.68 \\
Sweden & 79.7 & 79.8 & 0.91 & 75.0 & 0.88 & 57.8 & 0.15 \\
Germany & 78.4 & 67.7 & 0.91 & 63.0 & 0.88 & 54.7 & 0.01 \\
USA & 59.1 & 49.9 & 0.87 & 44.3 & 0.81 & 34.4 & 0 \\
France & 57.6 & 43.3 & 0.91 & 37.1 & 0.83 & 28.9 & 0 \\
South Korea & 39.3 & 27.3 & 0.84 & 21.8 & 0.76 & 17.0 & 0.03 \\
Taiwan & 37.0 & 30.6 & 0.77 & 27.6 & 0.68 & 22.8 & 0.21 \\
Brazil & 27.3 & 20.7 & 0.89 & 15.5 & 0.78 & 13.7 & 0.2 \\
India & 27.3 & 19.4 & 0.73 & 16.9 & 0.58 & 12.1 & 0 \\
\hline
\end{tabular}

Notes: ${ }^{1}$ Electoral democracy index (V-Dem, 2005); ${ }^{2}$ Liberal democracy index (V-Dem, 2005), ${ }^{3}$ Direct popular vote index (V-Dem, 2005). Database: WVS 2005-2007. 
The higher the value, the more the democracy of each country conforms to the normative model and the higher the objective quality of that democracy. We start with the description of the subjective data and then move on to the objective data.

As the subjective democracy indices are constructed in such a way that the more demanding models presuppose the less demanding ones, the level of subjective quality of democracy successively decreases from "Democracy (D)" to "Direct Democracy (DD)". In Table 2, the countries are ordered according to the level of support for "Democracy (D)".

The most striking feature of the distribution of the subjective quality of democracy is the significant differences between the countries. This is already true for the basic support of democracy as a form of government, i.e. "Democracy (D)". The minimal subjective quality of democracy is the highest in Norway $(81.7 \%)$ and the lowest in India and Brazil (27.3\%). Notably, the values of all established Western countries, i.e. the five European countries and the USA, are above the 50-percent-level, while the values of the remaining non-European countries are below.

The pattern is similar for "Electoral Democracy (ED)", where Norway shows the highest $(74.2 \%)$ and India $(19.4 \%)$ the lowest degree of subjective quality. Even though all countries are classified as liberal democracies, the data for the subjective quality of "Liberal Democracy (LD)" reveal considerable differences. Only four European countries (Norway, Switzerland, Sweden, and Germany) exceed the 50-percent-level and with the exception of the USA, all non-European countries reveal support levels below $30 \%$.

Country differences are also large for the subjective quality of "Direct Democracy (DD)". The lowest figures can be found in India (12.1\%) and the highest level of subjective quality of direct democracy is-as expected-in Switzerland (62.2\%). Interestingly, the values for Sweden and Germany are also above the 50-percent-level. Overall, the established Western democracies show higher values than the other non-Western countries and the differences within the first group of countries are much higher than in the second group. While in the established Western democracies values range from $28.9 \%$ (France) to $62.2 \%$ (Switzerland), support for direct democracy in the other non-Western countries varies only from $12.1 \%$ (India) to $22.8 \%$ (Taiwan). Obviously, it is difficult to interpret the pattern for the subjective quality of direct democracy without objective data on the degree of institutionalization of direct democracy.

As an initial conclusion, we can state that the data reveal significant differences regarding the subjective quality of all three models of democracy. The lowest levels exist for non-Western democracies. Applying less strict criteria in dichotomizing the indicators would indeed result in higher percentages for the subjective quality of democracy but the substantial differences between the countries as well as the ranking of countries would remain.
What about the objective quality of democracy in the selected European and non-European countries? For electoral and liberal democracy, the differences between the countries at the objective level are considerably lower compared to the subjective level. For electoral democracy, only the figures of Taiwan and India are below 0.80 . The liberal democracy index reveals two thresholds, one which separates Western from non-Western countries (above and below 0.80 , respectively) and the other within the non-Western countries where India clearly differs from the rest (below 0.68).

In order to measure the objective quality of direct democracy we do not draw on the very broadly defined participatory democracy index of V-Dem; instead, the direct popular vote index is used (Coppedge et al., 2017, pp. 52-53, 62-63). It corresponds to the subjective indicator asking for approval of referendums. The most striking result for this objective measurement is that only Switzerland has a notable value (0.68). This reflects the fact that in other countries direct democracy or referendums are not or are hardly institutionalized. However, it is noteworthy that despite the low degree of institutionalization of direct democracy, the subjective quality score is between 44 and $57.8 \%$ in several countries (Norway, Sweden, and Germany). This can be interpreted as citizens' demand for the introduction of referendums into the institutional setting of the liberal democracy of their country.

The most important result of the comparison between objective and subjective measures of the quality of democracy is the following: differences between countries at the objective level are considerably lower than at the subjective level. This implies different things for the various models of democracy. First, with respect to electoral and liberal democracy, this can mean, among other things, that even a successful institutionalization of an electoral or liberal democracy in a country does not, at the same time, ensure a corresponding level of citizens' commitment to democratic values and principles. Such a configuration is already known from democratization research, where democratic consolidation encompasses not only the existence of democratic institutions but also support of democracy by the main political actors (Diamond, 1999; Linz \& Stepan, 1996). A commitment to democratic values and principles depends on different historical traditions and different cultural contexts (Fuchs \& Roller, 2016), it cannot be directly generated by implementing democratic institutions. Second, with respect to direct democracy, a reverse pattern exists between the subjective and objective quality of democracy. The discrepancy between both dimensions can mean that citizens demand that the institutional setting of liberal democracy in their country is complemented with instruments of direct democracy.

\section{Conclusions}

The aim of the article is to contribute to the current discussion on assessing the quality of democracy in several 
ways. First, by arguing that a measurement of the subjective quality of democracy is reasonable. We start from the assumption that the basic postulate of the concept of political culture, according to which support of democracy is of relevance for the stability and functioning of a democracy, can be expanded to the subjective quality of democracy as well. Second, by conceptualizing the subjective quality of democracy as support for different models of democracy (distinguishing between three established normative models, i.e. electoral, liberal and direct democracy) and not as citizens' evaluation of democracy in their country. Accordingly, the more citizens support normative conceptions of democracy, the higher the subjective quality of a democracy. Third, by developing an instrument measuring the suggested dimensions of the quality of democracy for European and non-European democracies. Fourth, by demonstrating the applicability of this instrument and providing initial empirical results. Fifth, by comparing these results with objective measurements provided by V-Dem. The comparison of the subjective with the objective quality of democracy for the electoral, liberal and direct models of democracy shows that at the objective level the differences between the countries are significantly lower than those at the subjective level. Hence, the subjective perspective of citizens is not fully determined by the objective institutions and processes. For the subjective perspective, historical traditions and cultural contexts play a crucial role.

The proposed measurement for assessing the subjective quality of democracy is preliminary, it is not claimed to be the final solution. For future research, at least three desiderata remain. First, the validity of our measurement instrument should be examined using multiple indicators for each model of democracy. This could be done, at least for European countries, on the basis of the European Social Survey 2012 which includes several indicators for the different models of democracy. Second, supplementing the subjective quality of democracy by including support for normative conceptions of democratic community, i.e. the relationship between citizens such as tolerance toward other groups and trust in unknown others. Empirically, it could be demonstrated that the largest differences between Western and non-Western countries exist for these normative conceptions of democratic community (Fuchs \& Roller, 2016). Third, a measurement instrument could be developed to combine the objective and subjective dimensions of quality of democracy.

\section{Conflict of Interests}

The authors declare no conflict of interests.

\section{References}

Almond, G. A., \& Verba, S. (1963). The civic culture. Princeton, NJ: Princeton University Press.

Altman, D. (2011). Direct democracy worldwide. Cambridge: Cambridge University Press.
Altman, D. (2013). Bringing direct democracy back in: Toward a three-dimensional measure of democracy. Democratization, 20(4), 615-641.

Bühlmann, M., Merkel, W., Müller, L., \& Weßels, B. (2012). The democracy barometer: A new instrument to measure the quality of democracy and its potential for comparative research. European Political Science, 11(4), 519-536.

Coppedge, M., Gerring, J., Altman, D., Bernhard, M., Fish, S., Hicken, A., . . . Teorell, J. (2011). Conceptualizing and measuring democracy: A new approach. Perspectives on Politics, 9(2), 247-267.

Coppedge, M., Gerring, J., Lindberg, S., Skaaning, S.-E., Altman, D., Bernhard, M., ... Staton, J. (2017). V-Dem Codebook v7.1. Retrieved from https://www.vdem.net/media/filer_public/84/a8/84a880ae-e0ca4ad3-aff8-556abfdaff70/v-dem_codebook_v71.pdf

Coppedge, M., Lindberg, S., Skaaning, S.-E., \& Teorell, J. (2016). Measuring high level democratic principles using the V-Dem Data. International Political Science Review, 37(5), 580-593.

Dahl, R. A. (1989). Democracy and its critics. New Haven, CT: Yale University Press.

Dalton, R. J. (2004). Democratic challenges, democratic choices. Oxford: Oxford University Press.

Diamond, L. (1999). Developing democracy. Baltimore, MD: Johns Hopkins University Press.

Easton, D. (1975). A re-assessment of the concept of political support. British Journal of Political Science, 5(4), 435-457.

Ferrín, M., \& Kriesi, H. (Eds.). (2016). How Europeans view and evaluate democracy. Oxford: Oxford University Press.

Freedom House. (2017). Freedom in the world. Freedom House. Retrieved from http://www.freedom house.org

Fuchs, D. (2007). The political culture paradigm. In R. J. Dalton \& H.-D. Klingemann (Eds.), The Oxford handbook of political behaviour (pp. 161-184). Oxford: Oxford University Press.

Fuchs, D., \& Roller, E. (2016). Demokratiekonzeptionen der Bürger und demokratische Gemeinschaftsorientierungen [Citizens' conceptions of democracy and democratic community]. In S. Schubert \& A. Weiss (Eds.), "Demokratie" jenseits des Westens ["Democracy" beyond the West] (pp. 296-317). Baden-Baden: Nomos.

Goertz, G. (2006). Social science concepts: A user's guide. Princeton, NJ: Princeton University Press.

Klingemann, H.-D. (2014). Dissatisfied democrats. In R. J. Dalton \& C. Welzel (Eds.), The civic culture transformed (pp. 116-157). Cambridge: Cambridge University Press.

Levitsky, S., \& Way, L. A. (2010). Competitive authoritarianism. Cambridge: Cambridge University Press.

Linz, J. J., \& Stepan, A. (1996). Problems of democratic transition and consolidation. Baltimore, MD: Johns Hopkins University. 
Lipset, S. M. (1981). Political man. Baltimore, MD: The Johns Hopkins University Press.

Mayne, Q., \& Geissel, B. (2016). Putting the demos back into the concept of democratic quality. International Political Science Review, 37(5), 634-644.

Merkel, W. (2004). Embedded and defective democracies. Democratization, 11(5), 33-58.

Merkel, W., Bochsler, D., Bousbah, K., Bühlmann, M., Giebler, H., Hänni, M., . . Wessels, B. (2016). Democracy barometer. Codebook. Version 5. Aarau: Zentrum für Demokratie.

Morlino, L. (2009). Are there hybrid regimes? Or are they just an optical illusion? European Political Science Review, 1(2), 273-296.

Munck, G. L. (2009). Measuring democracy. Baltimore, MD: The Johns Hopkins University Press.
Munck, G. L., \& Verkuilen, J. (2002). Conceptualizing and measuring democracy: Evaluating alternative indices. Comparative Political Studies, 35(1), 5-34.

Norris, P. (2011). Democratic deficit. Cambridge: Cambridge University Press.

O’Donnell, G. A. (1994). Delegative democracy. Journal of Democracy, 5(1), 55-69.

Pickel, S., Breustedt, W., \& Smolka, T. (2016). Measuring the quality of democracy: Why include the citizens' perspective? International Political Science Review, 37(5), 645-655.

Putnam, R. (1993). Making democracy work. Princeton, NJ: Princeton University Press.

Schedler, A. (Eds.). (2006). Electoral authoritarianism. Boulder, CO: Lynne Rienner.

\section{About the Authors}
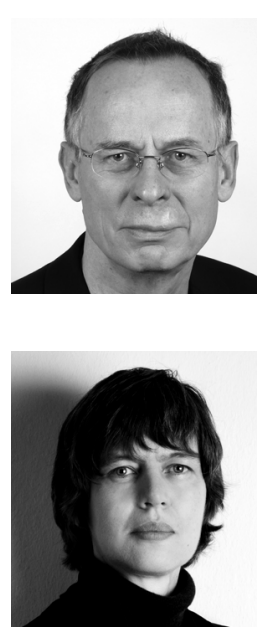

Dieter Fuchs is Professor Emeritus of Political Science at the University of Stuttgart. His research mainly focusses on democratic theory, comparative analysis of political cultures, and European integration.

Edeltraud Roller is Professor of Political Science at the Johannes Gutenberg University Mainz. Her research mainly focusses on welfare state cultures, the performance of democracies, and political support within old and new democracies. 